\title{
Article \\ Redox Mechanism of Azathioprine and Its Interaction with DNA
}

\author{
Mihaela-Cristina Bunea ${ }^{1,2}$, Victor-Constantin Diculescu ${ }^{1}$, Monica Enculescu ${ }^{1}$ (D) Horia Iovu ${ }^{2}$ and \\ Teodor Adrian Enache 1,* \\ 1 Laboratory of Multifunctional Materials and Structures, National Institute of Materials Physics, Atomistilor \\ 405A, 077125 Magurele, Romania; mihaela.bunea@infim.ro (M.-C.B.); victor.diculescu@infim.ro (V.-C.D.); \\ mdatcu@infim.ro (M.E.) \\ 2 Advanced Polymer Materials Group, University Politehnica of Bucharest, 1-7 Gh. Polizu, 011061 Bucharest, \\ Romania; iovu@tsocm.ro \\ * Correspondence: adrian.enache@infim.ro
}

Citation: Bunea, M.-C.; Diculescu,

V.-C.; Enculescu, M.; Iovu, H.; Enache, T.A. Redox Mechanism of Azathioprine and Its Interaction with DNA. Int. J. Mol. Sci. 2021, 22, 6805. https://doi.org/10.3390/ijms22136805

Academic Editor: Andrew G. Ewing

Received: 26 May 2021

Accepted: 16 June 2021

Published: 24 June 2021

Publisher's Note: MDPI stays neutral with regard to jurisdictional claims in published maps and institutional affiliations.

Copyright: (C) 2021 by the authors. Licensee MDPI, Basel, Switzerland. This article is an open access article distributed under the terms and conditions of the Creative Commons Attribution (CC BY) license (https:// creativecommons.org/licenses/by/ $4.0 /)$.

\begin{abstract}
The electrochemical behavior and the interaction of the immunosuppressive drug azathioprine (AZA) with deoxyribonucleic acid (DNA) were investigated using voltammetric techniques, mass spectrometry (MS), and scanning electron microscopy (SEM). The redox mechanism of AZA on glassy carbon (GC) was investigated using cyclic and differential pulse (DP) voltammetry. It was proven that the electroactive center of AZA is the nitro group and its reduction mechanism is a diffusion-controlled process, which occurs in consecutive steps with formation of electroactive products and involves the transfer of electrons and protons. A redox mechanism was proposed and the interaction of AZA with DNA was also investigated. Morphological characterization of the DNA film on the electrode surface before and after interaction with AZA was performed using scanning electron microscopy. An electrochemical DNA biosensor was employed to study the interactions between AZA and DNA with different concentrations, incubation times, and applied potential values. It was shown that the reduction of AZA molecules bound to the DNA layer induces structural changes of the DNA double strands and oxidative damage, which were recognized through the occurrence of the 8-oxo-deoxyguanosine oxidation peak. Mass spectrometry investigation of the DNA film before and after interaction with AZA also demonstrated the formation of AZA adducts with purine bases.
\end{abstract}

Keywords: azathioprine; redox mechanism; DNA biosensor; DNA interaction; mass spectrometry

\section{Introduction}

The medical use of azathioprine (6-([1-methyl-4-nitro-1Himidazol-5-yl]-sulphonyl)7H-purine, AZA), which metabolically breaks down to 6-mercaptopurine in the human body, dates back to 1963 [1,2]. Being a purine analog, AZA blocks purine metabolism and DNA synthesis, and in recent times has been administrated as an immunosuppressive (mainly to prevent renal transplant rejection) and antileukemic drug to treat autoimmune diseases such as ulcerative colitis, rheumatoid arthritis, dermatitis, lupus erythematosus, and Crohn's disease [3-5]; however, there have been many reports about the high risk of skin cancer for patients exposed to solar radiation under AZA treatment, a fact that limits the administration of AZA [6-10]. In order to decrease this side effects, appropriate experimental models should be investigated at the laboratory level, and after the underlying principles are understood, integrated with pharmaceutical studies. Generally, the biological processes are governed by the electron transfer reactions, which means that the electrochemical methods can successfully be used to simulate complex in vivo biochemical interactions. In order to sustain the pharmacokinetics studies, one of the aims of this study was to investigate the electrochemical behavior and electron transfer mechanism of AZA, using cyclic and differential pulse voltammetry on a glassy carbon electrode. 
To date, electrochemical studies have been performed investigating the voltammetric behavior of AZA, but a complete redox mechanism has not been proposed to date [11-13]. Several scientific articles have shown the improvement of azathioprine detection limits using various modified sensing platforms based on graphene, which can be decorated with Ag nanoparticles, incorporated into natural polymers such as chitosan, or functionalized with ionic liquids [12,14-16]. Glassy carbon electrodes are another type of surface that are widely used for the development of new sensors with nanodiamond-graphite chitosan film or with carbon nanoparticle-nafion film in order to improve the sensitivity of the voltammetric determination of azathioprine [14,15].

On the other hand, DNA damage and its interaction with biologically active molecules are important fundamental issues in life science. The achievement of more efficient targeted pharmaceutics has been the subject of recent investigations, based on DNA-drug interaction [17-19]. The interaction of DNA with endobiotics or xenobiotics can take place via various mechanisms, which may be assisted by enzymatic reactions [20-23]. Among the chemical reactions that are not catalytically assisted, it is worth highlighting the electrostatic interactions and the intercalation of chemical molecules between DNA strands, which results in conformational modifications of the secondary structure of DNA [24,25].

Over the last decades, electrochemical biosensors have been proven to be reliable analytical tools for the elucidation of the interaction mechanisms of DNA with pharmaceutical compounds [26-29]. The advantages offered by electrochemical biosensors over other screening methods include the possibility for automation and real-time analysis, improved reproducibility and speed, and low production costs [27,30-32].

In this context, the goal of this study was the investigation of DNA-AZA interaction using electrochemical DNA biosensors, scanning electron microscopy, and mass spectrometry. The novelty of this study was the use of DNA electrochemical biosensors for the investigation of morphological DNA modifications upon interaction with AZA. Biosensors based on dsDNA, poly (A), and poly $(\mathrm{G})$ were used to investigate the AZA-DNA interaction. The electrochemical characterization of the in situ interaction of AZA with DNA or purine bases on a glassy carbon modified electrode combined with mass spectrometry and scanning electron microscopy provided essential information about the effects of this drug on DNA.

\section{Materials and Methods}

\subsection{Reagents and Solutions}

Azathioprine (AZA), 1 methyl-4 nitro-imidazole (IMI), 6-mercaptopurine (Merc), double-strand DNA (dsDNA), polyadenylic acid (poly(A)), and polyguanylic acid potassium salt $(\operatorname{poly}(G))$ were acquired from Sigma-Aldrich.

According to the supplier, dsDNA (catalogue number D1501) is extracted using a method that causes shearing, yielding a highly polymerized mixture of double- and singlestranded DNA. The double-stranded DNA is the predominant form. The base distribution for DNA from calf thymus samples is $41.9 \mathrm{~mol} \% \mathrm{G}-\mathrm{C}$ and $58.1 \mathrm{~mol} \%$ A-T. Poly(A) (catalogue number P9403) was prepared from adenosine diphosphate (ADP) with polynucleotide phosphorylase, while poly $(\mathrm{G})$ (catalogue number P4404) was synthetically produced in Thermus thermophilus from guanosine diphosphate (GDP). All of the substances were used without further purification.

The electrolyte solutions of acetate buffer $(\mathrm{pH}=4.5)$, phosphate buffer $(\mathrm{pH}=7)$, and ammonia buffer $(\mathrm{pH}=9)$ were prepared with analytical-grade reagents and purified water from a Milli-Q system (conductivity of less than $0.1 \mu \mathrm{S} \mathrm{cm}{ }^{-1}$ ).

The stock solution of AZA was prepared daily in DMSO and kept at $4{ }^{\circ} \mathrm{C}$ and protected from light. Solutions of different concentrations of azathioprine were prepared by dilution of the appropriate quantity in the desired buffer. All experiments were carried out in a dark environment.

Stock solutions of $35 \mathrm{mg} \mathrm{mL}^{-1}$ dsDNA and $3.5 \mathrm{mg} \mathrm{mL}^{-1}$ poly(A) and poly(G) were prepared in purified water. 
All experiments were performed at room temperature $\left(25 \pm 1^{\circ} \mathrm{C}\right)$.

\subsection{Instrumentation}

\subsubsection{Electrochemical Measurements}

The measurements were performed using a computer-controlled Ivium potentiostat with IviumSoft version 2.219 (Ivium Technologies, Eindhoven, The Netherlands). Measurements were carried out using a glassy carbon working electrode $(d=1.6 \mathrm{~mm}), \mathrm{at}$ wire counter, and an $\mathrm{Ag} / \mathrm{AgCl}(3 \mathrm{M} \mathrm{KCl})$ reference electrode in a single-compartment $2 \mathrm{~mL}$ electrochemical cell. Before each experiment, the GCE was polished using diamond spray (particle size $1 \mu \mathrm{m}$ ) on a microcloth pad, rinsed with Milli-Q water, and electrochemically pre-treated by recording various DP voltammograms in buffer-supporting electrolyte until a steady-state baseline voltammogram was obtained. All measurements were performed in $\mathrm{N}_{2}$-saturated solutions in the dark in order to prevent the UV degradation of the immunossupresive drug.

Cyclic voltammetry (CV) was performed for scan rates ranging from 10 to $500 \mathrm{mV} \mathrm{s}^{-1}$ with a $2 \mathrm{mV}$ step potential from $\mathrm{E}_{\text {start }}=0 \mathrm{~V}, \mathrm{E}_{\min }=-1 \mathrm{~V}$, and $\mathrm{E}_{\max }=1.4 \mathrm{~V}$. Differential pulse (DP) voltammetry values were recorded with a pulse amplitude of $50 \mathrm{mV}$, pulse width of $100 \mathrm{~ms}$, and scan rate of $5 \mathrm{mV} \mathrm{s}^{-1}$. All of the presented voltammograms were background-subtracted and baseline-corrected using the IVIUM soft program tools. This mathematical treatment reduces the peak heights by up to $10 \%$ and was used for the presentation of all experimental voltammograms to allow easier and clearer identification of the peaks. The values for peak currents presented in all graphs were determined from the original untreated voltammograms.

\subsubsection{Field-Emission Scanning Electron Microscopy (FESEM)}

The morphology of the samples was investigated using a Gemini 500 Carl Zeiss fieldemission scanning electron microscope (FESEM) working in both high-vacuum (HV) and variable-pressure (VP) modes from 0.2 to $30 \mathrm{kV}$, equipped with LaB6 filament, InLens and SE2 detectors, NanoVP mode, and a Bruker QUANTAX 200 energy-dispersive X-ray spectrometer (EDS) with an XFlash ${ }^{\circledR} 6$ silicon drift detector (SDD), an energy resolution $<129 \mathrm{eV}$ at $\mathrm{Mn}-\mathrm{Ka}$, and Peltier cooling. The above setup was used to investigate the elemental compositions of the samples.

\subsubsection{Mass Spectrometry}

All mass spectra were acquired using an ESI ion source Bruker Daltonik amaZon speed ion trap mass spectrometer (Bruker Daltonik, Bremen, Germany). The ion source was operated in positive mode with nitrogen as the drying gas, with a flow rate of $5 \mathrm{~L} / \mathrm{min}$ at $180{ }^{\circ} \mathrm{C}$, nebulizer pressure of $7.5 \mathrm{psi}$, capillary voltage of $4.5 \mathrm{kV}$, and end plate offset of $0.5 \mathrm{kV}$. Optimum ion transfer was achieved by automatically running the system smart parameter setting in order to optimize the ion transfer for the desired $m / z$ value. Charge control of the ion trap was activated with a target value of 200,000 and a maximum accumulation time of $10 \mathrm{~ms}$. Samples of $1 \mathrm{mM}$ azathioprine in methanole were injected directly into the mass spectrometer at a flow rate of $180 \mu \mathrm{L} \mathrm{h}^{-1}$. Mass spectra were recorded for $m / z$ values between 50 and 380 at $5200 \mathrm{amu} / \mathrm{s}$ in maximum resolution scan mode and ten scans were averaged into one mass spectrum.

\subsection{Biosensor Preparation and Incubation Procedure}

The DNA biosensors were obtained by covering the GC surface with one $2 \mu \mathrm{L}$ drop containing $35 \mathrm{mg} \mathrm{mL}^{-1}$ dsDNA gel and allowed to dry in air. For control experiments, poly $(\mathrm{G})$ and poly $(\mathrm{A})$ biosensors were prepared following the same protocol. The incubation procedure consisted of immersion of the biosensors for different periods of time in solutions with various concentrations of AZA in $\mathrm{pH} 4.50 .1 \mathrm{M}$ acetate buffer with or without an applied voltage $(-0.600 \mathrm{~V})$. After this procedure, the electrode was rinsed with purified 
water in order to remove the weakly bound or unbound molecules and measured in acetate buffer using the DPV method.

The acidic digestion of DNA before and after incubation with AZA involved removal of the DNA film from the electrode surface; thus, the DNA film weighing about $350 \mu \mathrm{g}$ (10 $\mu \mathrm{L}$ drop containing $35 \mathrm{mg} \mathrm{mL}^{-1}$ dsDNA gel) was removed mechanically from the electrode surface and treated with $\mathrm{HClO}_{4} 9 \mathrm{M}$ over $10 \mathrm{~min}$. The digestion was stopped with $\mathrm{NaOH} 9 \mathrm{M}$ after 10 min digestion. All digested DNA samples were diluted with purified water and subjected to MS spectrometry.

\section{Results and Discussion}

The objective of this investigation was to understand the interactions between AZA and DNA by using dsDNA electrochemical biosensors. The first part of this study was dedicated to the understanding of the electrochemical behavior of AZA through comparative studies with 1-methyle-4-nitro imidazole, using voltammetric techniques and a GC electrode. In the second part of the study, the DNA electrochemical biosensors were used in order to observe changes of the conformation of the DNA immobilized at the GC electrode surface. Different DNA-based biosensors, such as dsDNA, poly(A), and poly $(\mathrm{G})$, were used for the investigation of AZA-DNA interaction. The electrochemical results were correlated with morphological characterization using FESEM and mass spectrometry investigations.

\subsection{Azathioprine Redox Behavior}

\subsubsection{Voltammetric Analysis}

Cyclic voltammograms taken at the GC electrode at a scan rate of $100 \mathrm{mVs}^{-1}$ were recorded in $0.1 \mathrm{M} \mathrm{pH} 4.5$ acetate buffer containing $500 \mu \mathrm{M}$ AZA between the negative potential limit $E_{\min }=-1.0 \mathrm{~V}$ and the positive potential limit $E_{\max }=+1.40 \mathrm{~V}$.

When scanning toward positive potential values, on the first positive-going scan of the first voltammogram (Figure 1A), no oxidation reaction appeared, showing that AZA is not electroactive at the experimental conditions. When reversing the scan direction, on the negative-going component of the first voltammogram, a reduction peak $1_{\mathrm{c}}$ appeared at $E_{\mathrm{pc}}$ $=-0.62 \mathrm{~V}$. Subsequently, on the second voltammogram recorded in the same solution and without cleaning the electrode surface, two new anodic peaks, $2_{\mathrm{a}}$ and $3_{\mathrm{a}}$, appeared at $E_{\mathrm{pa}}$ $=+0.45 \mathrm{~V}$ and $E_{\mathrm{pa}}=+1.35 \mathrm{~V}$, respectively, corresponding to the electrochemical oxidation of the AZA reduction product. Additionally, a new cathodic charge transfer reaction, $2_{c}$, occurring at $E_{\mathrm{pc}}=-0.25 \mathrm{~V}$ was observed.
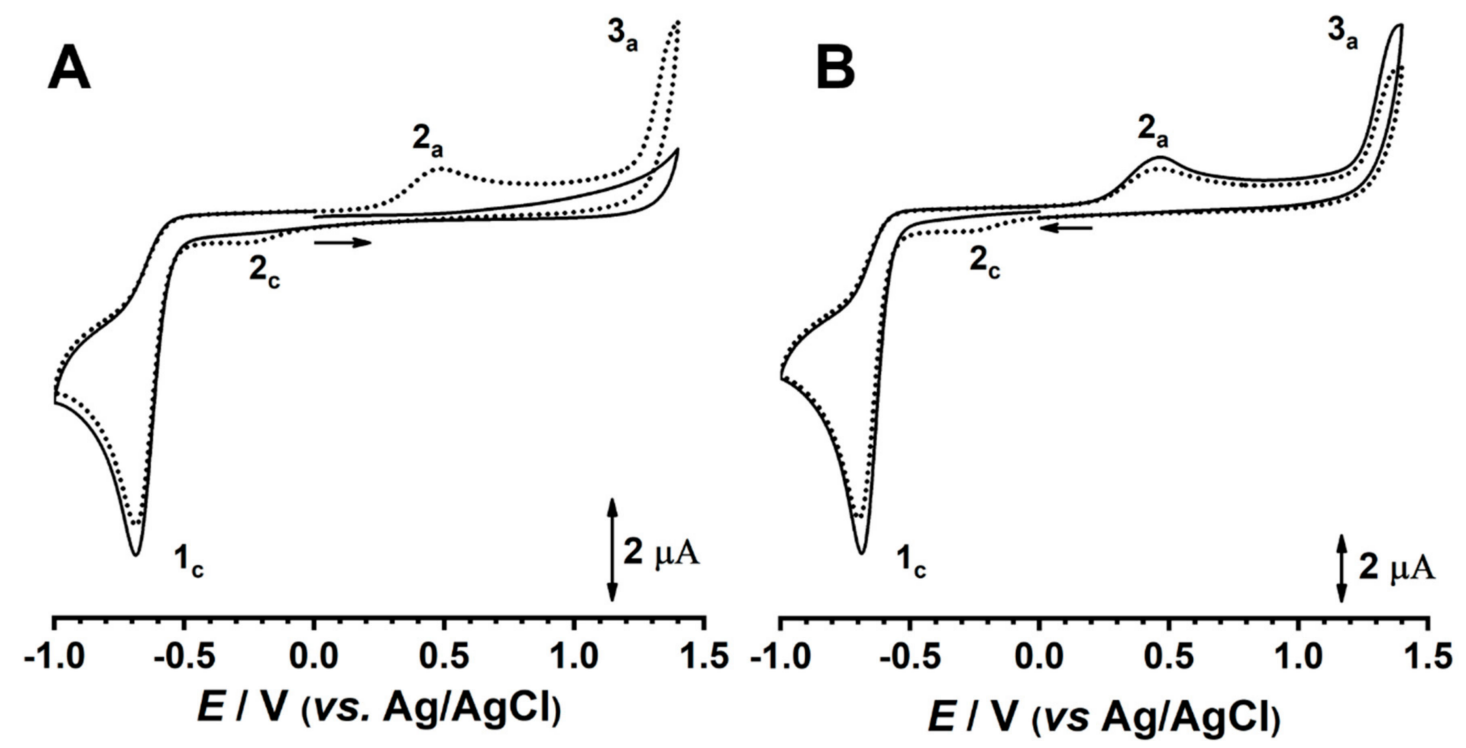

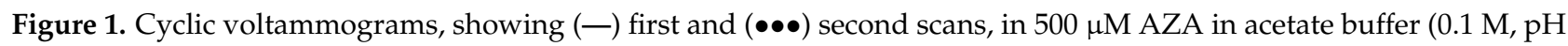
4.5): (A) positive-going and (B) negative-going scans at $v=50 \mathrm{mVs}^{-1}$. 
A new experiment was performed in similar conditions using a clean GC electrode surface but scanning toward negative potential values (Figure 1B). The cathodic peak $1_{\mathrm{c}}$ appeared at $E_{\mathrm{pc}}=-0.62 \mathrm{~V}$, and after changing the scan direction the two anodic charge transfer reactions, $2_{\mathrm{a}}$ and $3_{\mathrm{a}}$, appeared at $E_{\mathrm{pa}}=+0.45 \mathrm{~V}$ and $E_{\mathrm{pa}}=+1.35 \mathrm{~V}$, respectively. Additionally, on the second scan, the reduction peak $2_{\mathrm{c}}$ occurred at $E_{\mathrm{pc}}=-0.25 \mathrm{~V}$. By increasing the $\mathrm{pH}$ of the electrolyte (Figure 2), all redox potentials of AZA shifted linearly to less positive potentials, while $\Delta \mathrm{E}_{\mathrm{p}}$ of the $\mathrm{2}_{\mathrm{a}} / \mathrm{2}_{\mathrm{c}}$ pair remained constant.

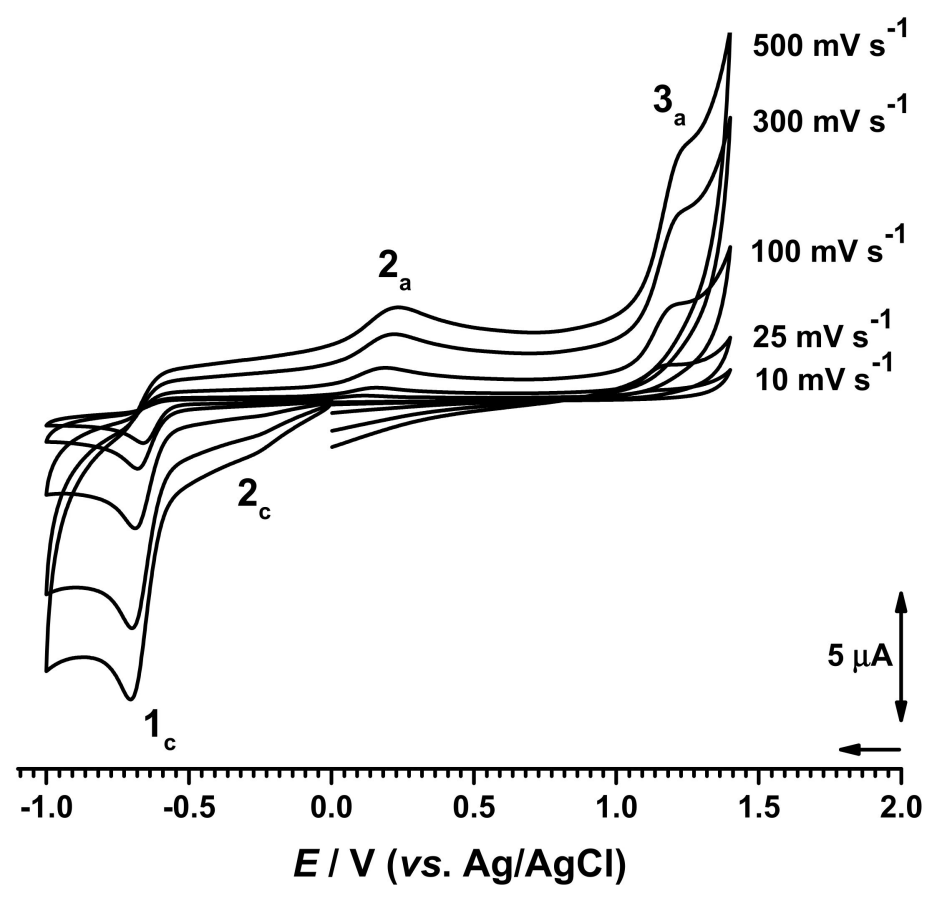

Figure 2. Cyclic voltammograms at different scan rates in $500 \mu \mathrm{M}$ AZA in phosphate buffer $(0.1 \mathrm{M}$, $\mathrm{pH}=7.0)$.

Nevertheless, the effects of dissolved oxygen on the origin of peak $2_{c}$ were investigated at different $\mathrm{pHs}$ using normal oxygen content and $\mathrm{O}_{2}$-bubbled solutions (Figure S1). The results revealed that the appearance of the $2_{c}$ peak was not influenced by the presence of the $\mathrm{O}_{2}$ in the electrochemical cell (Figure $\mathrm{S} 1$ ).

The effect of the scan rate on the reduction current of AZA was investigated in a $500 \mu \mathrm{M}$ AZA solution prepared in phosphate buffer $(0.1 \mathrm{M}, \mathrm{pH}=7.0$; Figure 2$)$. The cyclic voltammograms were recorded for a scan rate of $10<v<500 \mathrm{mVs}^{-1}$. Between measurements, the electrode surface was polished in order to ensure the surface was clean and to avoid possible problems related to the adsorption of AZA or AZA redox products onto the GCE surface. The cyclic voltammograms revealed that the reduction current increased linearly with the increase of the square root of the scan rate and the peak potential shifts toward more negative values, suggesting an irreversible diffusioncontrolled process.

According to the Randles-Sěvcik equation, the peak current in amperes for a diffusioncontrolled irreversible system is given by [33]:

$$
I_{\mathrm{pc}}(\mathrm{A})=-0.4463\left(F^{3} / R T\right)^{1 / 2} \times n \times\left(\alpha_{\mathrm{c}} n^{\prime}\right)^{1 / 2} \times A \times[c]_{\infty} \times D_{0}{ }^{1 / 2} \times v^{1 / 2}
$$

where $n$ is the number of electrons exchanged in the reduction, $\alpha_{\mathrm{c}}$ is the transfer coefficient, $A$ is the surface area of the electrode $\left(\mathrm{cm}^{2}\right)$, and $[c]_{\infty}$ is the concentration of the electroactive species in mole $\mathrm{cm}^{-3}$. The difference between the peak potential $E_{\mathrm{pc}}$ and the potential at peak half-height $E_{\mathrm{pc} / 2}$ was $\sim 60 \mathrm{mV}$. For a diffusion-controlled irreversible system $\left|E_{\mathrm{pc}}-E_{\mathrm{pc} / 2}\right|=47.7 /\left(\alpha_{\mathrm{c}} n^{\prime}\right)$ where $\alpha_{\mathrm{c}}$ is the cathodic charge transfer coefficient and $n^{\prime}$ the number of electrons in the rate-determining step, $\alpha_{c} n^{\prime}=0.8$. For this calculation, the 
electroactive surface area of the GC electrode was calculated using the diffusion coefficient of hexacyanoferrate (II) in phosphate buffer at $D_{0}=7.35 \times 10^{-6} \mathrm{~cm}^{2} \mathrm{~s}^{-1}$ [33]. Using the above equation, the diffusion coefficient for $D_{0}=5.20 \times 10^{-5} \mathrm{~cm}^{2} \mathrm{~s}^{-1}$ was calculated.

The diffusion coefficient for AZA was also determined using the Wilke-Chang equation $[34,35]$ :

$$
D_{0}=7.4 \times 10^{-8} \times T \times\left(\alpha_{s v} \times M_{\mathrm{sv}}\right)^{-1 / 2} \times\left(\eta \times V_{\mathrm{b}, \mathrm{a}}{ }^{0.6}\right)^{-1}
$$

where $T$ is the absolute temperature $(\mathrm{K}), \alpha_{s v}$ is the association coefficient, $M_{s v}$ is the molecular weight, $\eta$ is the viscosity, and $V_{\mathrm{b}, \mathrm{a}}$ is the molar volume at the normal boiling point. A value of $D_{0}=1.22 \times 10^{-5} \mathrm{~cm}^{2} \mathrm{~s}^{-1}$ was obtained.

The effect of the $\mathrm{pH}$ on the redox behavior of AZA at the GC electrode was investigated using cyclic and DP voltammetry in 100 and $500 \mu \mathrm{M}$ solutions of AZA in supporting electrolytes with different $\mathrm{pH}$ values (Figure 3). The voltammetric results showed that the peak potentials shifted negatively with increasing $\mathrm{pH}$, which suggests that protons participate in the reduction process for azathioprine. For reduction peak $1_{c}$, the negative shift potential was close to the theoretical value of $59.2 \mathrm{mV}$ per $\mathrm{pH}$ unit, meaning that the reduction of AZA involved the same number of electrons and protons; however, although the value of the width at the half-height of the peak was around $75 \mathrm{mV}$, taking into consideration the previous reports on nitro-derivative compounds, the number of electrons involved was considered to be 2 .
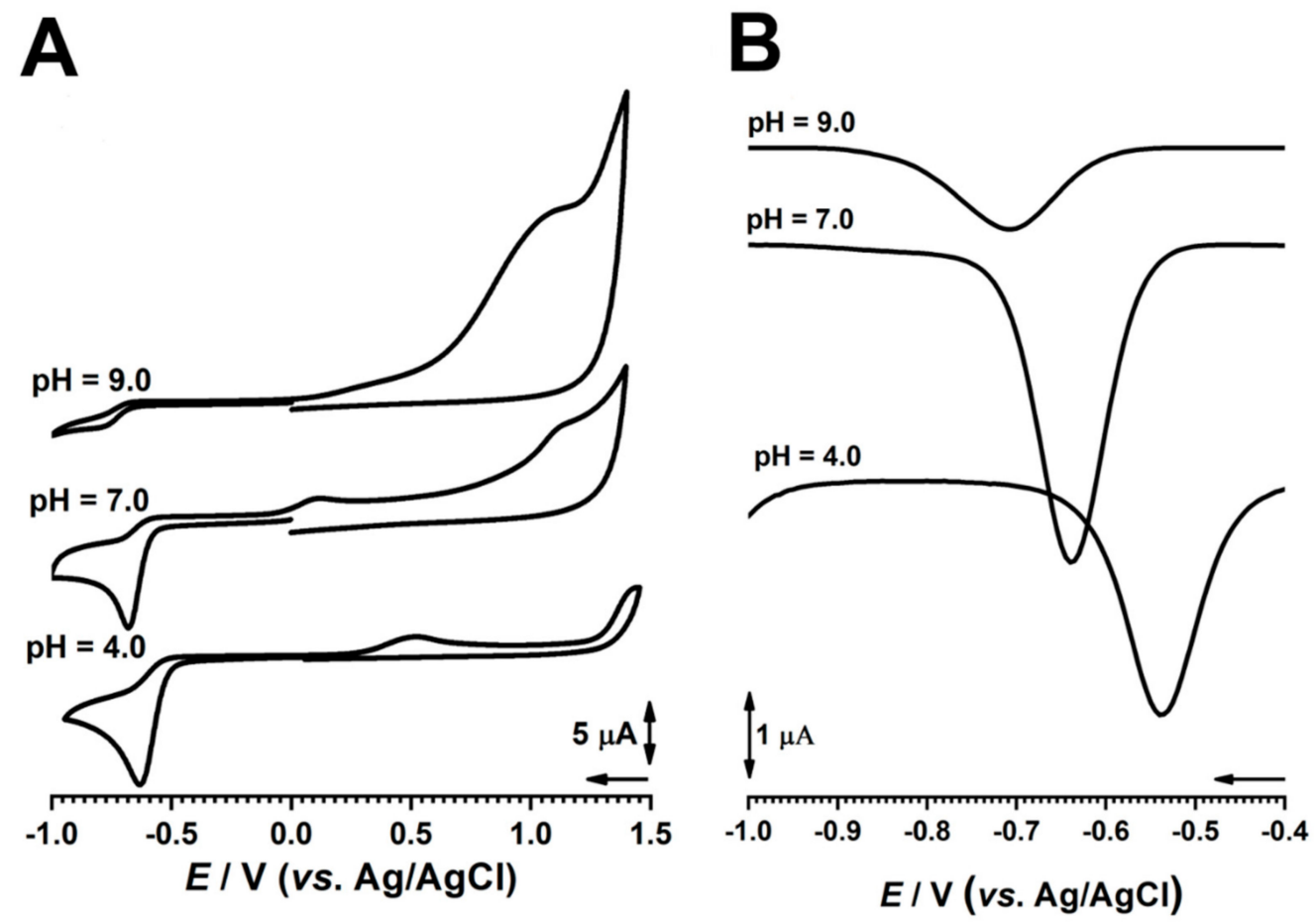

Figure 3. (A) CV at $v=100 \mathrm{mV} \mathrm{s}^{-1}$ and (B) DPV in $500 \mu \mathrm{M}$ AZA in electrolytes with different $\mathrm{pH}$ values.

Nevertheless, considering the fact that the stock solutions of AZA contained a large amount of DMSO, cyclic voltammograms were recorded in several electrolytes containing DMSO (Figure S2). It was observed that the addition of DMSO did not influence the voltammetric response.

\subsubsection{Redox Mechanism}

The results presented above showed that AZA undergoes reduction in one step, leading to the formation of reduction products, which in turn undergo oxidation at positive potential values. From a structural point of view, AZA is composed of two main moieties: 1-metyl-4-nitro imidazole and 6-mercaptopurine. In order to understand the redox mechanism, cyclic voltammograms for AZA and its moieties were recorded at the GC electrode 
in acetate buffer at $\mathrm{pH} 4.5$, with potential limits ranging between $-1.00 \mathrm{~V}$ and $+1.40 \mathrm{~V}$ and at $v=100 \mathrm{mV} \mathrm{s}^{-1}$. The results are compared in Figure 4 .

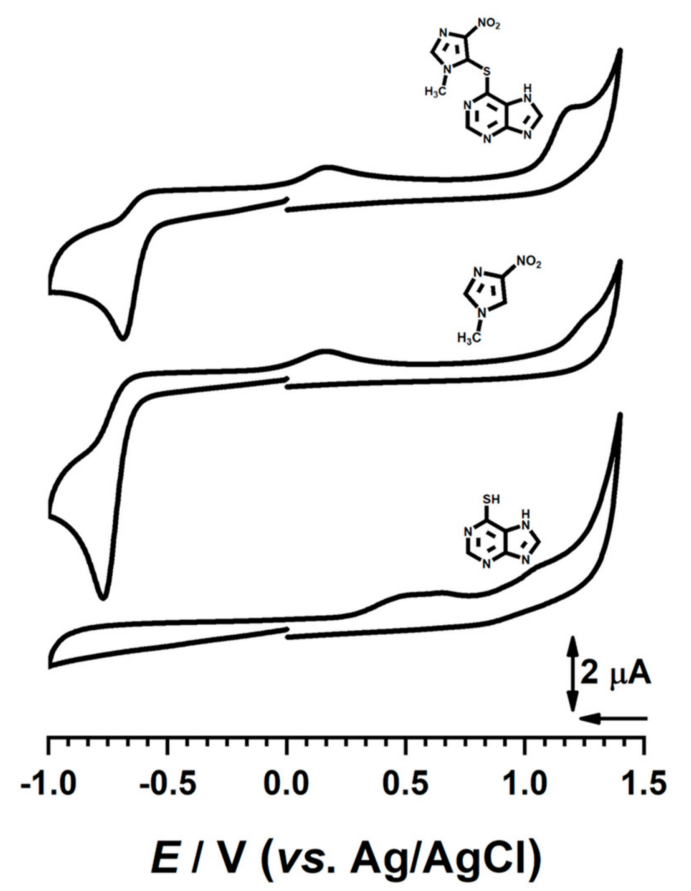

Figure 4. Cyclic voltammograms in $500 \mu \mathrm{M}$ azathioprine (Aza), 4 methyl-1-nitro-imidazole (Imi), and 6-mercaptopurine (Merc) in acetate buffer $\left(0.1 \mathrm{M}, \mathrm{pH}=7, v=100 \mathrm{mV} \mathrm{s}^{-1}\right)$.

Although the 6-mercaptopurine undergoes redox reactions, none of the peaks observed for this compound were identified in the CV recorded for AZA. In fact, the voltammetric behavior of AZA was dominated by that of 1-metyl-4-nitro imidazole. It is proposed that AZA was electrochemically reduced to compound (2), peak $1_{c}$, through a process involving 2 electrons and 2 protons (Scheme 1), followed by a coupled chemical reaction mechanism involving2 electrons and 2 protons for the conversion of the $\mathrm{NO}_{2}$ group to dihydroxylamine, which is unstable and undergoes dehydration to compound (3). In turn, compound (3) undergoes a quasireversible redox reaction, as demonstrated by the presence of a pair of peaks $2_{c}$ and $2_{a}$; on the other hand, irreversible oxidation at higher positive potential values leads to compound (5), a reaction responsible for peak $3 a$ of AZA.

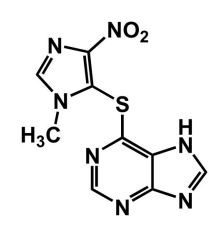

AZA

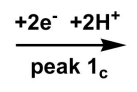<smiles></smiles>

(2)

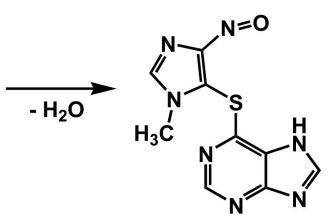

(3)

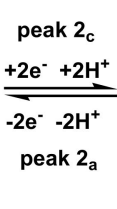

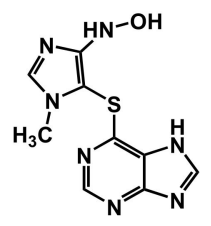

(4)
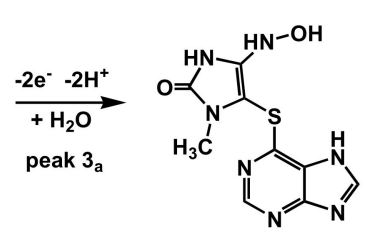

(5)

Scheme 1. Proposed redox mechanism of AZA.

In order to confirm the fact that the origin of the peak $2_{c}$ is not related to peak $3_{\mathrm{a}}$, cyclic voltammograms were obtained at $\mathrm{pH} 7.0$ in $500 \mu \mathrm{M}$ AZA after the reduction potential of $-0.60 \mathrm{~V}$ was applied for $30 \mathrm{~s}$. By recording the voltammograms between the potential limits of $E_{0}=0, E_{\min }=0.70 \mathrm{~V}$, and $E_{\max }=-0.40 \mathrm{~V}$ at different scan rates $(100,500,1000$, and $1500 \mathrm{mV} \mathrm{s}^{-1}$ ), the $2_{\mathrm{a}}-2_{\mathrm{c}}$ redox pair was observed (Figure S3). 


\subsection{Azathioprine-DNA Interaction}

\subsubsection{Morphological Characterization}

Morphological characterization of the dsDNA electrochemical biosensors was performed using FESEM (Figure 5) in order to highlight the modification of the DNA after interaction with AZA.
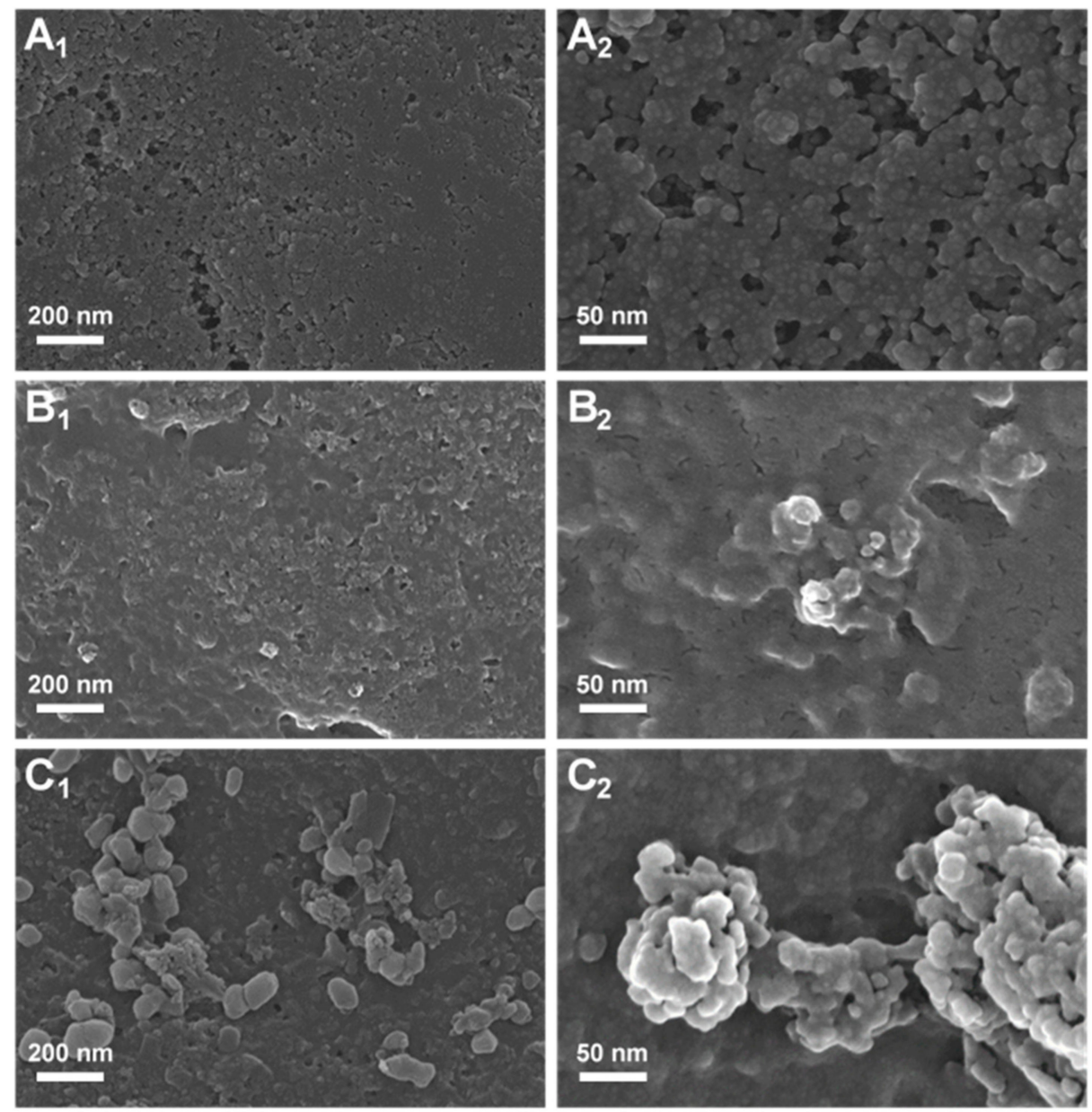

Figure 5. SEM images at (1) 50,000 and (2) 200,000 magnification: (A) electrode surface; the dsDNA biosensor (B) before and (C) after incubation in $500 \mu \mathrm{M}$ AZA.

Figure 5A depicts the highly porous surface of the screen-printed electrode. The image of the surface of the DNA biosensors (Figure 5B) revealed the spread of dsDNA molecules on the surface of the electrode and its complete coverage, which is essential in order to avoid the non-specific adsorption of drug molecules and to maintain the morphology of the screen-printed electrode. After incubation of the DNA with $1 \mathrm{mM}$ AZA over $20 \mathrm{~min}$, the FESEM image (Figure $5 \mathrm{C}$ ) showed the formation of clusters due to the action of the immunosuppresive drug; thus, AZA accumulated on the surface of the dsDNA-modified electrode and this process led to highly branched microstructures resulting from the smaller interconnected aggregates. The SEM images obtained for DNA biosensor incubated with AZA showed reorganization of the dsDNA molecules on the electrode surface, i.e., a more densely packed structure. Such behavior (i.e., a reorganization of the dsDNA molecules in a more densely packed structure) on the electrode surface was also observed for dsDNA after interaction with other molecules [20].

\subsubsection{DNA Electrochemical Biosensor}

To evaluate the ability of AZA to cause conformational changes, e.g., hydrogen bonding cleavage, dsDNA base adducts, or oxidative damage, the AZA-dsDNA interaction 
was investigated using DP voltammetry. The changes in the dsDNA oxidation peaks for desoxyguanosine (dGuo) and desoxyadenosine (dAdo) in the presence and in the absence of AZA were investigated, along with the occurrence of the oxidation peaks of free guanine (Gua), free adenine (Ade), and the guanine and adenine oxidation products, 8-oxoGua and 2,8-oxoAde.

Initial experiments were performed after incubation of the dsDNA electrochemical biosensor in a solution of $100 \mu \mathrm{M}$ AZA. After the incubation procedure, the biosensor surface was washed with deionized water in order to remove the loosely-bound AZA molecules and then placed into the electrochemical cell, which contained only buffered electrolyte. DP voltammograms were recorded in both positive and negative potential ranges (Figures S4 and S5). The DP voltammogram recorded for the DNA biosensor incubated for $10 \mathrm{~min}$ with $100 \mu \mathrm{M}$ AZA (Figure S4, blue line) showed that the oxidation of the DNA bases occurred with the same oxidation current as for the DNA control biosensor (Figure S4, black line); however, the incubation of the DNA biosensor with AZA under a negative applied potential of $-0.60 \mathrm{~V}$ (the reduction potential of AZA) resulted in an increase of the oxidation currents of guanosine and adenosine bases (Figure S4, red dotted line). This procedure was chosen for the investigation of the DNA-AZA interaction. After the incubation of the DNA biosensor with $100 \mu \mathrm{M}$ AZA under applied potential, the biosensor surface was washed with deionized water, transferred in supporting electrolytes at $\mathrm{pH} 4.5$, then DP voltammograms were recorded between $E_{\mathrm{i}}=-0.20 \mathrm{~V}$ and $E_{\mathrm{f}}=-0.90$ $\mathrm{V}$. The results showed the presence of an AZA reduction peak, with the reduction current decreasing with increasing applied potential time (Figure S5).

In a different experiment, the dsDNA electrochemical biosensor was incubated in a solution of $100 \mu \mathrm{M}$ AZA at an applied potential of $-0.60 \mathrm{~V}$ for different durations (Figure 6A). At this potential value, the AZA molecules that diffuse through the solution toward the electrode surface are reduced and the reduction products interact with the immobilized dsDNA layer. It is important to note that each experiment was performed with a new biosensor in order to avoid accumulation of AZA and its reduction products within the immobilized DNA layer.
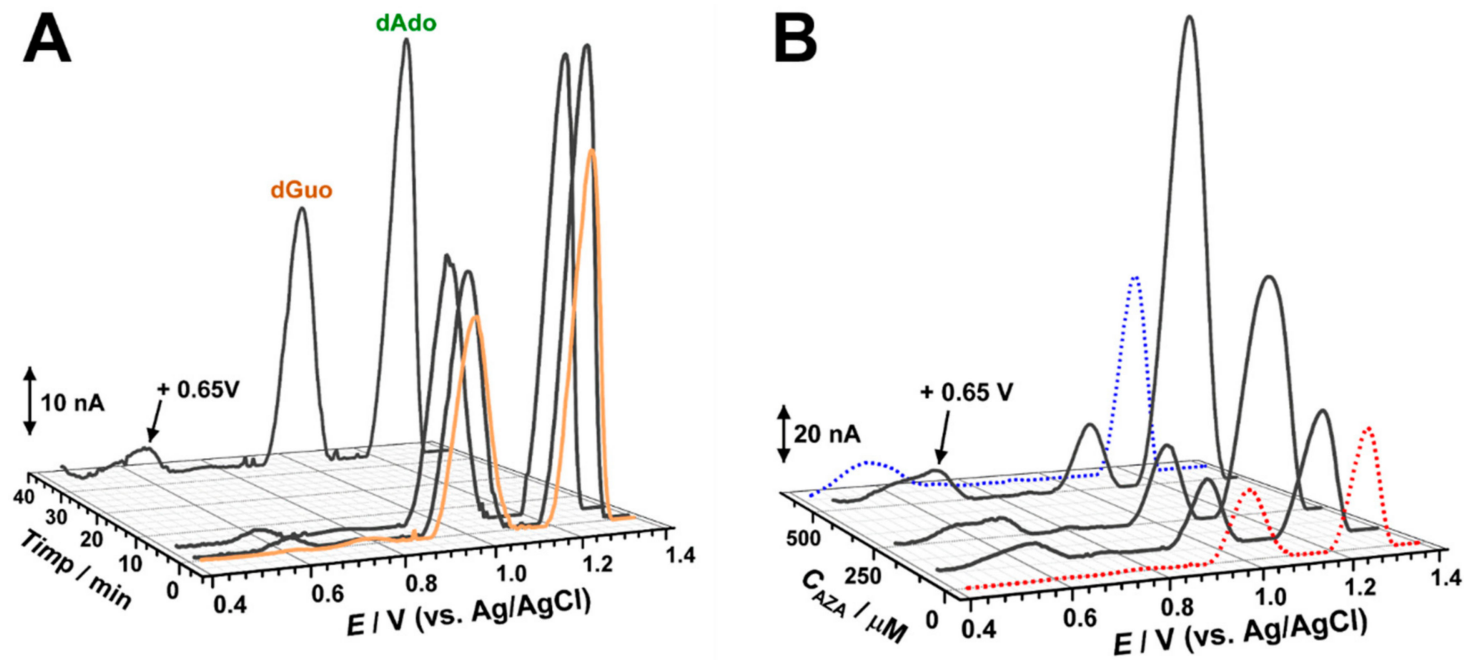

Figure 6. DP voltammograms in acetate buffer (0.1 M, pH 4.5) with the dsDNA biosensor after incubation at $-0.60 \mathrm{~V}$ : (A) in $100 \mu \mathrm{M}$ AZA for 1, 5, and $35 \mathrm{~min}$; (B) in 100, 250, and $500 \mu \mathrm{M}$ AZA for $10 \mathrm{~min}$. Note: the red dotted curve represents the DP voltammogram with the dsDNA biosensor after incubation at $-0.60 \mathrm{~V}$ in buffer; the blue dotted curve represents the DP voltammogram in AZA after applying $-0.60 \mathrm{~V}$.

The voltammograms recorded in these conditions after different incubation times showed increases of the dGuo and dAdo oxidation peaks, in agreement with the unwinding of the dsDNA double helix and exposure of the guanine and adenine residues to the electrode surface. At the same time, at $+0.65 \mathrm{~V}$ a new oxidation peak appeared, and at high 
incubation times it overlapped with peak $2_{a}$, which corresponded to the oxidation of the AZA reduction product.

The next electrochemical experiments were performed and the dsDNA electrochemical biosensors was incubated at an applied potential of $-0.60 \mathrm{~V}$ for $10 \mathrm{~min}$ in solutions of different concentrations of AZA (Figure 6B). In these conditions, both dGuo and dAdo oxidation peaks gradually increased with the AZA concentration, but a higher increase was observed for adenine residues. A similar effect was detected for the peak at $+0.65 \mathrm{~V}$.

In order to gain insights into the origin of the peak at $+0.65 \mathrm{~V}$, DNA electrochemical biosensors of known primary sequences were used. For this, purine homopolynucleotide single-stranded poly(A) and poly $(\mathrm{G})$ electrochemical biosensors were constructed and tested to assess interactions with AZA (Figure 7).
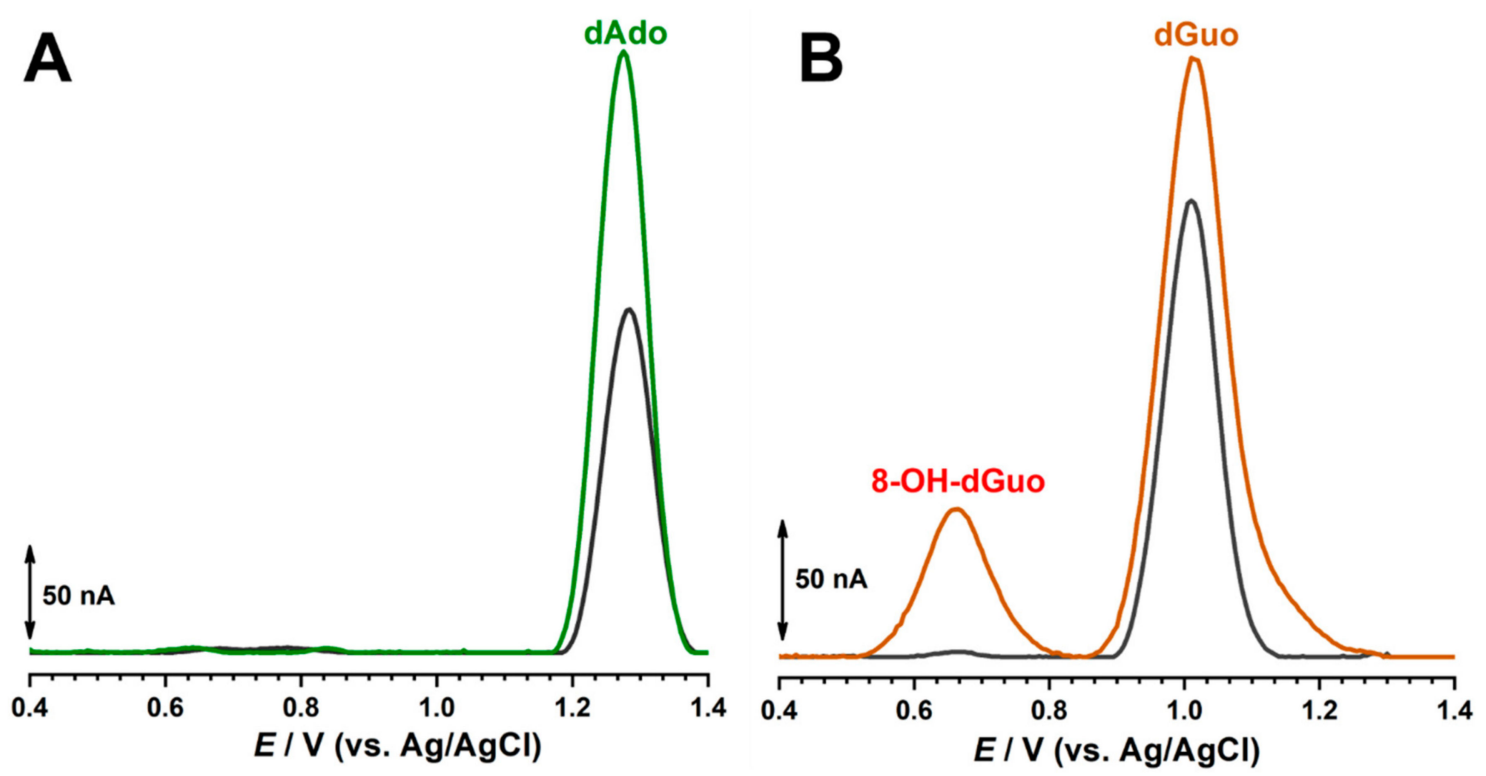

Figure 7. DP voltammograms in acetate buffer $(0.1 \mathrm{M}, \mathrm{pH} 4.5)$ with different biosensors: $(\mathbf{A})$ poly $(\mathrm{A})$ and $(\mathbf{B}) \mathrm{poly}(\mathrm{G})$ biosensors before (grey curves) and after incubation (green and orange curves, respectively) in $500 \mu \mathrm{M}$ AZA over 10 min.

The DP voltammogram in $0.1 \mathrm{M}$ acetate buffer at $\mathrm{pH} 4.5$ for the poly(A) electrochemical biosensor showed one anodic peak at $+1.28 \mathrm{~V}$, corresponding to the oxidation of dAdo (Figure 7A). A newly prepared poly(A) electrochemical biosensor was incubated for $10 \mathrm{~min}$ in $500 \mu \mathrm{M}$ of AZA at an applied potential of $-0.60 \mathrm{~V}$. In these conditions, the adenine residue oxidation peak increased but no other addition signal was observed [36].

The DP voltammogram in $0.1 \mathrm{M}$ acetate buffer at $\mathrm{pH} 4.5$ for the poly $(\mathrm{G})$ electrochemical biosensor showed one anodic peak at $+1.01 \mathrm{~V}$, corresponding to the oxidation of dGuo (Figure 7B). A newly prepared poly $(\mathrm{G})$ electrochemical biosensor was incubated for $10 \mathrm{~min}$ in $500 \mu \mathrm{M}$ of AZA at an applied potential of $-0.60 \mathrm{~V}$. The guanine residue oxidation peak increased and the peak at $+0.65 \mathrm{~V}$ occurred, corresponding to the formation of 8-oxo-dGuo, which causes oxidative damage to the guanine residues [37].

\subsubsection{Mass Spectrometry}

Drugs interact with DNA through several mechanisms. Among these, electrostatic binding, intercalation, and adduct formation predominate. Apart from the formation of 8oxo-dGuo, the experiments described above showed increases of the DNA oxidation peaks, especially in the case of adenine residues (although the contribution of AZA oxidation product 4 at peak 3a was not totally excluded), a characteristic effect of intercalation and adduct formation.

The possibility of adduct formation between DNA bases and AZA electrochemical products was investigated using mass spectrometry. For this investigation, the DNA film 
was removed from the surface of the biosensor after interaction with AZA at $-0.60 \mathrm{~V}$ and then subjected to acidic digestion as described in Section 2.3.

The MS spectra of the DNA before interaction with AZA showed signals corresponding to free DNA nucleosides, with $\mathrm{m} / \mathrm{z}$ values ranging between 225 and 270 , with the others being due to free phosphate and sugar groups resulting from the acidic digestion, as indicated in Figure 8A.

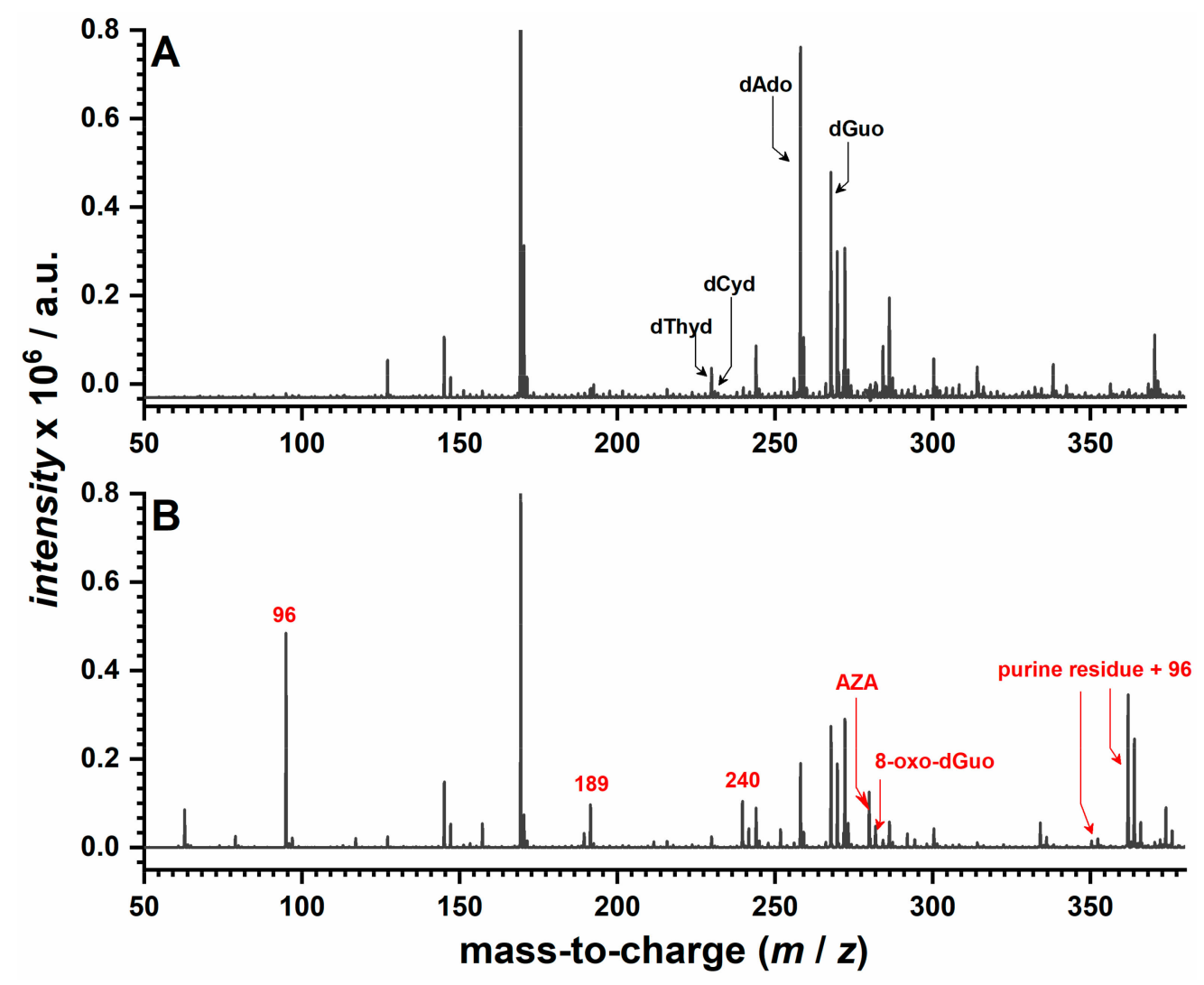

Figure 8. MS spectra for the acid-digested dsDNA: (A) before and (B) after incubation at $-0.60 \mathrm{~V}$ in $500 \mu \mathrm{M}$ AZA for $30 \mathrm{~min}$.

The MS spectra of the DNA after interaction with AZA showed signals characteristic of DNA as previously described, while additional peaks corresponding to AZA fragments were observed at 96, 189, 240, and $279 \mathrm{~m} / \mathrm{z}$ (Figure 8B). The presence of 8-oxo-dGuo was demonstrated one more time through the signal at the 283 mass-to-charge ratio. Additionally, the MS spectra recorded in these conditions showed new signals at 352 and $362 \mathrm{~m} / \mathrm{z}$, which were attributed to an adduct formation between purine residues and the AZA fragment responsible for the $96 \mathrm{~m} / z$ value.

\subsubsection{Interaction Mechanism}

The electrochemical experiments with the dsDNA, poly(G), and poly(A) electrochemical biosensors demonstrated conformational modifications within the DNA layer through the increase of both purine residue oxidation peaks after interaction with AZA at $-0.60 \mathrm{~V}$. This kind of behavior is typical for an interaction mechanism that involves either intercalation or adduct formation, processes that lead to unwinding of the DNA double helix, exposing the purine basis on the electrode surface, which facilitates their oxidation; however, the results presented above showed that AZA interacts with DNA through a complex mechanism.

The experiments carried out with the dsDNA and poly $(\mathrm{G})$ electrochemical biosensors demonstrated that upon reduction of AZA, 8-oxo-dGuo is formed within the DNA layer, which is a type of oxidative damage and a strong mutagenic compound. In order to explain the formation of the guanine oxidation product, it is proposed that upon applying the con- 
ditioning potential of $-0.60 \mathrm{~V}$, AZA molecules are reduced and the radical formed during this reaction oxidizes guanine residues, resulting in 8-oxo-dGuo formation (Scheme 2A).
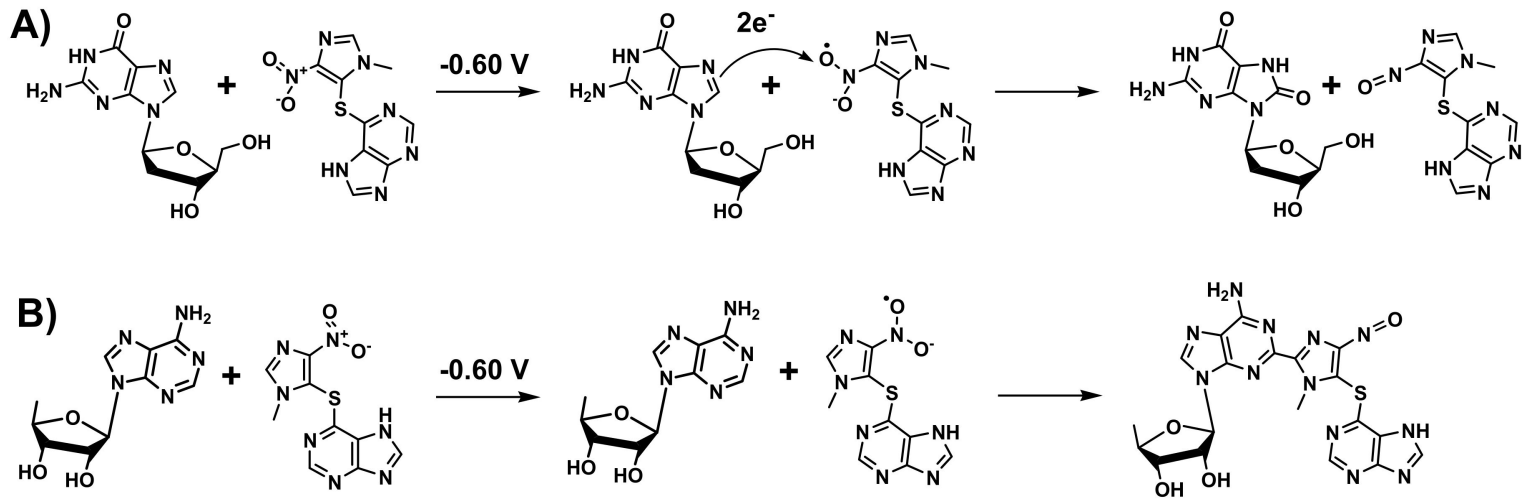

Scheme 2. Proposed mechanism of interaction of AZA with DNA bases: (A) formation of 8-oxo-deoxyguanosine and (B) adducts with adenine bases.

On the other hand, the experiments carried out with the poly(A) electrochemical biosensors showed a different behavior. Since this adenine residue in DNA is oxidized at a higher applied potential than guanine, it is proposed that upon applying the conditioning potential of $-0.60 \mathrm{~V}$, AZA molecules were reduced and the radical formed during this reaction was stabilized through the interactions with amino groups of adenine and guanine residues, resulting in the formation of adducts (Scheme 2B). In order to prove this interaction mechanism, MS spectra were recorded, demonstrating the formation of an adduct between purine bases and AZA. In fact, these types of DNA damage by AZA are documented in the literature [38,39], whereby nitropolycyclic aromatic compounds were reduced in situ, reacted with DNA, and subjected to NMR and LC-MS investigations, which demonstrated the formation of adducts with both guanine and adenine residues. Nonetheless, the formation of these types of adducts explains the increase of the DNA oxidation peaks upon interaction with AZA at $-0.60 \mathrm{~V}$.

\section{Conclusions}

The redox behavior of AZA was investigated on the GC electrode surface for a wide $\mathrm{pH}$ range using cyclic and differential pulse voltammetry, and a redox mechanism was proposed. It was shown that AZA undergoes reduction in one step, leading to the formation of reduction products, which in turn undergo oxidation at positive potential values. Nevertheless, DNA electrochemical biosensors were used for the investigation of the morphological modification of DNA upon the interaction with AZA. Different DNA-based biosensors, such as dsDNA, poly $(A)$, and poly $(G)$, were used for the investigation of the AZA-DNA interaction. The electrochemical results were correlated with morphological characterization using FESEM and mass spectrometry, demonstrating that upon reduction of AZA, 8-oxo-dGuo is formed within the DNA layer, which is a type of oxidative damage and a strong mutagenic compound. A mechanism for the AZA-DNA interaction was proposed.

Supplementary Materials: The following are available online at https:/ /www.mdpi.com/article/10 $.3390 / \mathrm{ijms} 22136805 / \mathrm{s} 1$.

Author Contributions: M.-C.B.: Investigation, formal analysis, data curation, visualization, writingoriginal draft. V.-C.D.: Methodology, supervision, visualization, writing-review and editing, funding acquisition. M.E.: Investigation, visualization, writing - review and editing. H.I.: Supervision. T.A.E.: Conceptualization, methodology, resources, writing - review and editing, supervision, funding acquisition. All authors have read and agreed to the published version of the manuscript. 
Funding: Financial support from the Operational Program for Competitiveness 2014-2020, project number NANOBIOSURF-SMIS 103528; and the Executive Agency for Higher Education and Research Funding (UEFISCDI) and the National Research Council (CNCS), project number PN-III-P1-1.2PCCDI-2017-0062/06.03.2018 (PCCDI 58/2018) within PNCDI III are gratefully acknowledged.

Conflicts of Interest: The authors declare no conflict of interest.

\section{References}

1. Hemmens, V.J.; Moore, D.E. Photochemical sensitization by azathioprine and its metabolites-i. 6-mercaptopurine. Photochem. Photobiol. 1986, 43, 247-255. [CrossRef]

2. Hoffmann, M.; Rychlewski, J.; Chrzanowska, M.; Hermann, T. Mechanism of activation of an immunosuppressive drug: Azathioprine. Quantum chemical study on the reaction of aza-thioprine with cysteine. J. Am. Chem. Soc. 2001, 123, 6404-6409. [CrossRef]

3. Maltzman, J.S.; Koretzky, G.A. Azathioprine: Old drug, new actions. J. Clin. Investig. 2003, 111, 1122-1124. [CrossRef]

4. Casetta, I.; Iuliano, G.; Filippini, G. Azathioprine for multiple sclerosis. Cochrane Database Syst. Rev. 2007, 4, 1-34. [CrossRef]

5. Miao, Q.; Bai, Y.J.; Zhang, J.L.; Li, Y.; Su, Z.Z.; Yan, L.; Wang, L.L.; Zou, Y.G. Highly sensitive and rapid determination of azathioprine metabolites in whole blood lysate by liquid chroma-tography-tandem mass spectrometry. J. Chromatogr. B Anal. Technol. Biomed. Life Sci. 2020, 1136, 121802. [CrossRef]

6. Moore, D.E. Principles and practice of drug photodegradation studies. J. Pharm. Biomed. Anal. 1987, 5, 441-453. [CrossRef]

7. Perrett, C.; Walker, S.; O'Donovan, P.; Warwick, J.; Harwood, C.; Karran, P.; McGregor, J. Azathioprine treatment photosensitizes human skin to ultraviolet A radiation. Br. J. Dermatol. 2008, 159, 198-204. [CrossRef]

8. Hemmens, V.J.; Moore, D.E. Photochemical Sensitization By Azathioprine and Its Metabo-lites-li. Azathioprine and Nitroimidazole Metabolites. Photochem. Photobiol. 1986, 43, 257-262. [CrossRef]

9. Zhang, Y.; Zhang, J.; Xiao, Y.; Chang, V.W.-C.; Lim, T.-T. Kinetic and mechanistic investigation of azathioprine degradation in water by UV, UV/H 2 O 2 and UV/persulfate. Chem. Eng. J. 2016, 302, 526-534. [CrossRef]

10. Ulrich, C.; Stockfleth, E. Azathioprine, UV light, and skin cancer in organ transplant patients do we have an answer? Med. Monatsschr. Pharm. 2000, 23, 261-266. [CrossRef]

11. Jalali, F.; Rasaee, G. Electrochemical, spectroscopic, and theoretical studies on the interaction between azathioprine and DNA. Int J. Biol. Macromol. 2015, 81, 427-434. [CrossRef]

12. Hatami, Z.; Jalali, F. Voltammetric determination of immunosuppressive agent, azathioprine, by using a graphene-chitosan modified-glassy carbon electrode. Russ. J. Electrochem. 2015, 51, 70-76. [CrossRef]

13. Shahrokhian, S.; Ghalkhani, M. Electrochemical study of Azathioprine at thin carbon nano-particle composite film electrode. Electrochem. Commun. 2009, 11, 1425-1428. [CrossRef]

14. Shahrokhian, S.; Ghalkhani, M. Glassy carbon electrodes modified with a film of nanodia-mond-graphite/chitosan: Application to the highly sensitive electrochemical determination of Azathioprine. Electrochim. Acta 2010, 55, 3621-3627. [CrossRef]

15. Barkat Rezaei, Z.; Rastegarzadeh, S.; Kiasat, A. In-situ decorated silver nanoparticles on elec-trospun poly (vinyl alcohol)/chitosan nanofibers as a plasmonic sensor for azathioprine deter-mination, Colloids Surfaces A Physicochem. Eng. Asp. 2018, 559, 266-274. [CrossRef]

16. Vais, R.D.; Sattarahmady, N.; Karimian, K.; Heli, H. Green electrodeposition of gold hierarchical dendrites of pyramidal nanoparticles and determination of azathioprine. Sens. Actuators B Chem. 2015, 215, 113-118. [CrossRef]

17. Kurbanoglu, S.; Dogan-Topal, B.; Rodriguez, E.P.; Bozal-Palabiyik, B.; Ozkan, S.A.; Uslu, B. Advances in electrochemical DNA biosensors and their interaction mechanism with pharma-ceuticals. J. Electroanal. Chem. 2016, 775, 8-26. [CrossRef]

18. Satana, H.E.; Pontinha, A.D.R.; Diculescu, V.C.; Oliveira-Brett, A.M. Nucleoside analogue electrochemical behaviour and in situ evaluation of DNA-clofarabine interaction. Bioelectrochemistry 2012, 87, 3-8. [CrossRef]

19. Oliveira-Brett, A.M.; Vivan, M.; Fernandes, I.R.; Piedade, J.A.P. Electrochemical detection of in situ adriamycin oxidative damage to DNA. Talanta 2002, 56, 959-970. [CrossRef]

20. Pontinha, A.D.R.; Jorge, S.M.A.; Paquim, A.M.C.; Diculescu, V.C.; Oliveira-Brett, A.M. In situ evaluation of anticancer drug methotrexate-DNA interaction using a DNA-electrochemical biosensor and AFM characterization. Phys. Chem. Chem. Phys. 2011, 13, 5227-5234. [CrossRef]

21. Buoro, R.M.; Lopes, I.C.; Diculescu, V.C.; Serrano, S.H.; Lemos, L.; Oliveira-Brett, A.M. In situ evaluation of gemcitabine-DNA interaction using a DNA-electrochemical biosensor. Bioelectrochemistry 2014, 99, 40-45. [CrossRef] [PubMed]

22. Rauf, S.; Gooding, J.; Akhtar, K.; Ghauri, M.; Rahman, M.; Anwar, M.; Khalid, A. Electrochemical approach of anticancer drugs-DNA interaction. J. Pharm. Biomed. Anal. 2005, 37, 205-217. [CrossRef] [PubMed]

23. Muti, M.; Muti, M. Electrochemical monitoring of the interaction between anticancer drug and DNA in the presence of antioxidant. Talanta 2018, 178, 1033-1039. [CrossRef] [PubMed]

24. Santos, P.V.F.; Lopes, I.C.; Diculescu, V.C.; Oliveira-Brett, A.M. DNA-Cyanobacterial Hepa-totoxins Microcystin-LR and Nodularin Interaction: Electrochemical Evaluation. Electroanalysis 2012, 24, 547-553. [CrossRef]

25. Brett, A.M.O.; Diculescu, V.C.; Paquim, A.M.C.; Serrano, S.H. Chapter 20 DNA-electrochemical biosensors for investigating DNA damage. Compr. Anal. Chem. 2007, 49, 413-437. 
26. Ozluer, C.; Kara, H.E.S. In vitro DNA binding studies of anticancer drug idarubicin using spectroscopic techniques. J. Photochem. Photobiol. B Biol. 2014, 138, 36-42. [CrossRef] [PubMed]

27. Oliveira-Brett, A.M.; Diculescu, V.C. Electrochemical study of quercetin-DNA interactions: Part II. In situ sensing with DNA biosensors. Bioelectrochemistry 2004, 64, 143-150. [CrossRef]

28. Karadurmus, L.; Kurbanoglu, S.; Uslu, B.; Özkan, S. Electrochemical DNA Biosensors in Drug Analysis. Curr. Pharm. Anal. 2017, 12, 1. [CrossRef]

29. Bagni, G.; Osella, D.; Sturchio, E.; Mascini, M. Deoxyribonucleic acid (DNA) biosensors for en-vironmental risk assessment and drug studies. Anal. Chim. Acta 2006, 573-574, 81-89. [CrossRef]

30. Cagnin, S.; Caraballo, M.; Guiducci, C.; Martini, P.; Ross, M.; SantaAna, M.; Danley, D.; West, T.; Lanfranchi, G. Overview of Electrochemical DNA Biosensors: New Approaches to Detect the Expression of Life. Sensors 2009, 9, 3122-3148. [CrossRef]

31. Diculescu, V.C.; Paquim, A.M.C.; Oliveira-Brett, A.M. Applications of a DNA-electrochemical biosensor. TrAC Trends Anal. Chem. 2016, 79, 23-36. [CrossRef]

32. Akbari Javar, H.; Garkani-Nejad, Z.; Dehghannoudeh, G.; Mahmoudi-Moghaddam, H. De-velopment of a new electrochemical DNA biosensor based on Eu3+-doped $\mathrm{NiO}$ for determi-nation of amsacrine as an anti-cancer drug: Electrochemical, spectroscopic and docking stud-ies. Anal. Chim. Acta. 2020, 1133, 48-57. [CrossRef] [PubMed]

33. Ngamchuea, K.; Eloul, S.; Tschulik, K.; Compton, R.G. Planar diffusion to macro disc elec-trodes-what electrode size is required for the Cottrell and Randles-Sevcik equations to apply quantitatively? J. Solid State Electrochem. 2014, 18, 3251-3257. [CrossRef]

34. Wilke, C.R.; Chang, P. Correlation of diffusion coefficients in dilute solutions. AIChE J. 1955, 1, 264-270. [CrossRef]

35. Miyabe, K.; Isogai, R. Estimation of molecular diffusivity in liquid phase systems by the Wilke-Chang equation. J. Chromatogr. A 2011, 1218, 6639-6645. [CrossRef] [PubMed]

36. Diculescu, V.C.; Piedade, J.A.P.; Oliveira-Brett, A.M. Electrochemical behaviour of 2,8-dihydroxyadenine at a glassy carbon electrode. Bioelectrochemistry 2007, 70, 141-146. [CrossRef]

37. Brett, A.M.O; Piedade, J.A.P.; Serrano, S.H.P. Electrochemical Oxidation of 8-Oxoguanine. Electroanalysis 2000, 12, 969-973. [CrossRef]

38. Fu, P.P.; Herreno-Saenz, D.; Von Tungeln, L.S.; Lay, J.O.; Wu, Y.S.; Evans, F.E. DNA adducts and carcinogenicity of nitro-polycyclic aromatic hydrocarbons. Environ. Health Perspect. 1994, 102, 177-183.

39. Ritter, C.L.; Culp, S.J.; Freeman, J.P.; Marques, M.M.; Beland, F.A.; Malejka-Giganti, D. DNA Adducts from Nitroreduction of 2,7-Dinitrofluorene, a Mammary Gland Carcinogen, Catalyzed by Rat Liver or Mammary Gland Cytosol. Chem. Res. Toxicol. 2002, 15, 536-544. [CrossRef] 